\title{
Effect of vibration on the scour process around cylindrical structures under unidirectional flow in a sandy bed
}

\author{
M. Al-Hammadi \\ PhD candidate, University College London, London, UK
}

R. R. Simons

Professor, University College London, London, UK

\begin{abstract}
The structures that support wind turbines in offshore wind farms are dynamically sensitive and can vibrate as a consequence of their slenderness and their location in severe environments subject to strong wind and wave load. The granular soils in which such structures are often located are highly responsive to vibrations; depending on their initial state, these soils might experience processes such as compaction, dilation, and liquefaction. Their behaviour in response to structural movement and the effect on the rate of scour is the subject of the present work. Laboratory experiments have been conducted to investigate the effects of vibration on the scour process in granular soil. A series of storms were simulated by a continuous sequence of periods with and without vibration applied to a model pile. The results show that although scour depths are initially reduced by vibration (backfilling), the lateral extent of the scour hole grows and the final scour depth and extent can be significantly greater than for an equivalent test without vibration.
\end{abstract}

\section{INTRODUCTION}

Offshore wind farms are considered an important element of future energy infrastructure. In a marine environment the presence of the structure on which a wind turbine is supported will change the natural flow pattern around it, enhance bed shear stresses, and may lead to scour development around the structure. This is particularly the case when the structure is located in a seabed of granular soil. Such structures are dynamically sensitive due to their slenderness, their location in severe environments subject to strong wind and wave load, and the fluctuating load induced by the rotating blades. Whether a scour hole around a dynamic structure will continue to develop, reach an equilibrium situation or backfill is a process governed by the local hydrodynamics and soil characteristics. Simplified scale modelling in laboratory flumes can help to advance understanding of the mechanisms for scour and the interactions between the fluid, structure, and sediment.

The majority of the literature on seabed scour relates to scour around static, rigid piles. The development of scour under a variety of hydrodynamic conditions and for different types of sediment is relatively well understood. Hoffmans \& Verheij (1997), Whitehouse (1998), Melville \& Coleman (2000), Sumer et al. (2001) and Sumer \& Fredsoe (2002) provide comprehensive summaries of the main findings of previous research. Marine soils respond to the structural movement caused by environmental loads. Bed sediments and consequently the scour process will be affected by dynamic movements. There are a number of studies covering the dynamics of wind turbines, soil-structure interaction and cyclic loading. Adhikari \& Bhattacharya (2010), Harte et al. (2012), Bhattacharya et al. (2013), Damgaard et al. (2014), Yu et al. (2014) and Foglia et al. (2015) reported a wide range of studies involving the cyclic loading of different types of sediment and the dynamic behaviour of wind turbines.

Comparatively little work has been reported relating to scour around dynamic structures, and most of this is to do with the structural dynamics rather than to the fluid-soil interaction. For instance, the effect of scour and backfilling on the natural frequency of the structural vibrations has been investigated by Damgaard et al. (2013) who developed a relationship connecting scour depth and backfilling height with Eigen frequency. The research reported here is part of a study focusing on the scour process taking into account the effects of vibration under a variety of hydrodynamic conditions and different bed materials. The aim of this study is to obtain a better understanding of scour development under these conditions to inform the design of offshore structures such as wind turbine foundations in the future.

\section{METHODOLOGY}

\subsection{Dynamic simulation:}

Vibration of actual piles in the field caused by environmental loads has been scaled to the size of the flume. The natural frequency of a structure is the key parameter in describing dynamic behaviour and can be estimated both by theoretical and experimental approaches. A formula suggested by Tempel \& Molenaar (2002) was used to estimate the natural frequency for a pile with a fixed base. This takes the form: 


$$
f_{1} \approx \sqrt{\frac{3.04 E I}{(M+0.227 m L) 4 \pi^{2} L^{3}}}
$$

where $f_{1}$ is the natural frequency of the system, EI pile bending stiffness, $M$ is the top mass, $m$ is the pile mass per metre and $\mathrm{L}$ is the unsupported length of pile. Therefore estimation of the natural frequency of a structure depends strongly on the pile geometry, material and the unsupported pile length. The estimation also assumes the pile end support as fixed and ignores the effect of the surrounding fluid in natural frequency evaluation.

The experimental measurement of the natural frequency of the test system was carried out as a free vibration test. This was done by applying a small excitation to the structure and recording the movement using an accelerometer fixed at the top of the structure (Fig. 1).

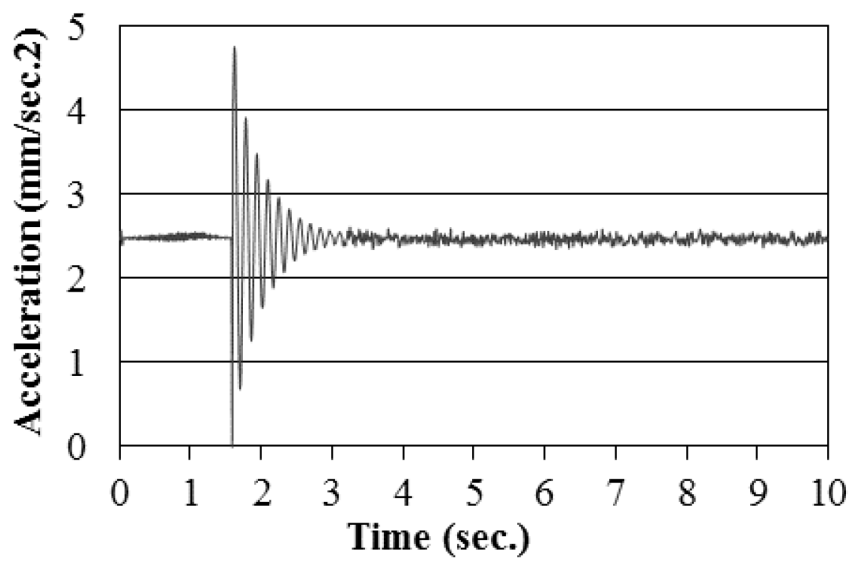

Figure 1: Free vibration data for pile (length $50 \mathrm{~cm}, 40 \mathrm{~mm}$ diameter).

\subsection{Storm Simulation:}

Offshore wind farms are designed to survive loading from extreme winds and waves. A storm observed at the port of Tampa in Florida which lasted for 61 hours has been chosen as the present case study (Phan et al., 2007). Storm duration, forcing frequency and top displacement were all scaled to reflect such environmental conditions in the laboratory.

\subsection{Granular soil-frequency sensitivity:}

Soil particles react in different ways to dynamic movement depending on the forcing frequency and amplitude of vibration. As a result pile stiffness is directly affected by the dynamic movement. Medium and loose dense sands tend to densify while most clays degrade, leading to lower pile stiffness.

In order to understand the relationship between the soil density and frequency of vibration two sand types, the coarse sample with $\mathrm{d}_{50}=0.62 \mathrm{~mm}$ and $\sigma_{\mathrm{g}}=$ 1.93, and the fine sand with $\mathrm{d}_{50}=0.2 \mathrm{~mm}$ and $\sigma_{\mathrm{g}}=$
1.44 , were employed. Five frequencies between 10 $\mathrm{Hz}$ and $50 \mathrm{~Hz}$ were examined.

A dynamic cone penetrometer presented by Herrick \& Jones (2002) was employed to measure the soil density after $5 \mathrm{~mm}$ amplitude vibrations of various frequencies were applied for 30 minutes. The penetrometer applies a known amount of kinetic energy to a cone. The number of blows required to penetrate a specified depth (for example $1 \mathrm{~cm}$ ) was measured and the results linked with the soil density.

Figure 2 shows the results obtained from the tests for five frequencies. This illustrates that the coarse sand responds to vibration and produces a significant difference in density depending on forcing frequency. The fine sand shows less sensitivity to change of forcing frequency and sediment density varies in a narrow range. A possible reason for this is that the coarse sand contains a variety of particle sizes in comparison with the fine sand which is more likely to be uniform and shows less sensitivity to vibration.

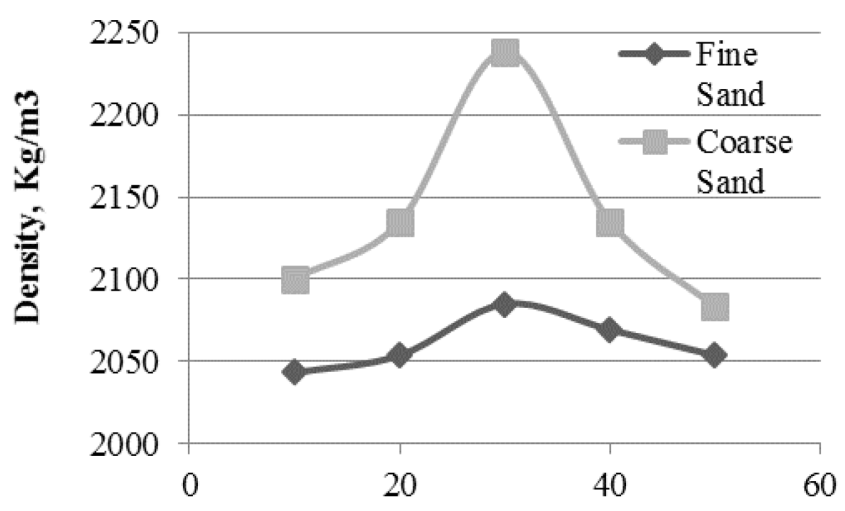

Vibration Frequency, $\mathrm{Hz}$

Figure 2: Density- Frequency relationship for two different sand samples.

For the soils in these tests it is clear that $30 \mathrm{~Hz}$ is the frequency of vibration that creates the highest change of density for both sand samples. This value was selected as the frequency of vibration and compaction for the present test programme.

\section{EXPERIMENTAL SETUP}

In order to investigate the effect of vibration on the scour process, experiments were undertaken in a reversing current flume $0.3 \mathrm{~m}$ wide and $10 \mathrm{~m}$ long. A $2 \mathrm{~m}$ false bed was installed over the width of the flume to retain the sediment bed. Two circular mono piles with diameters of $25 \mathrm{~mm}$ and $40 \mathrm{~mm}$ were tested. The centre line of each pile was located at the centre of the flume. Sand particles with median grain size $0.62 \mathrm{~mm}$ were used in these tests. The saturated sand was placed in the sediment pit and worked to eliminate air bubbles. The sand surface was then tamped and scraped using a scraper. Modelling of the environmental dynamic loads which act on a prototype offshore wind turbine was achieved using an 
electrodynamic actuator fixed rigidly to the model structure. Velocity measurements were made using a laser Doppler velocimeter (LDV). Measurement points were concentrated near the bed where there is a steeper velocity gradient, and fewer points in the upper part of the flow. All tests were conducted in the clear water regime. Flow depth was set at 165 $\mathrm{mm}$ for all tests. To investigate the effects of soil pre-compaction, vibration and a combination of the two on the local scour process, tests were conducted for two hydrodynamic cases. The next two sets of tests investigated the effects of vibration followed by a period without vibration for two pile sizes and hydrodynamic conditions. The last set contained a sequence of periods alternating between vibration and no vibration. The programme of tests and the test parameters are summarized in Table 1.

4 RESULTS
Table 1: Summary of the test program parameters.

\begin{tabular}{|c|c|c|c|c|c|c|c|}
\hline & $\underset{\Xi}{\Xi}$ & $\begin{array}{l}\underset{D}{D} \\
\text { D } \\
\Xi \\
\Xi \\
\Xi\end{array}$ & $z^{0}$ & 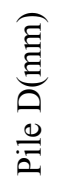 & 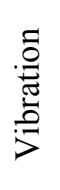 & 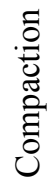 & 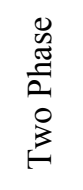 \\
\hline \multirow{4}{*}{$\begin{array}{l}\overrightarrow{0} \\
\ddot{0}\end{array}$} & 1 & 256 & 0.96 & 40 & - & - & - \\
\hline & 2 & 256 & 0.96 & 40 & $\checkmark$ & - & - \\
\hline & 3 & 256 & 0.96 & 40 & $\checkmark$ & $\checkmark$ & - \\
\hline & 4 & 256 & 0.96 & 40 & - & $\checkmark$ & - \\
\hline \multirow{4}{*}{$\begin{array}{l}N \\
\stackrel{0}{0}\end{array}$} & 5 & 232 & 0.88 & 40 & - & - & - \\
\hline & 6 & 232 & 0.88 & 40 & $\checkmark$ & - & $\checkmark$ \\
\hline & 7 & 232 & 0.88 & 40 & $\checkmark$ & $\checkmark$ & $\checkmark$ \\
\hline & 8 & 232 & 0.88 & 40 & - & $\checkmark$ & - \\
\hline \multirow{2}{*}{$\stackrel{n}{\stackrel{n}{\infty}}$} & 9 & 256 & 0.96 & 25 & - & - & - \\
\hline & 10 & 256 & 0.96 & 25 & $\checkmark$ & - & $\checkmark$ \\
\hline \multirow{2}{*}{$\begin{array}{l}\stackrel{+}{0} \\
\stackrel{\omega}{\infty}\end{array}$} & 11 & 232 & 0.88 & 25 & - & - & - \\
\hline & 12 & 232 & 0.88 & 25 & $\checkmark$ & - & $\checkmark$ \\
\hline \multirow{2}{*}{$\begin{array}{l}n \\
\tilde{\omega}\end{array}$} & 13 & 250 & 0.94 & 25 & - & - & - \\
\hline & 14 & 250 & 0.94 & 25 & 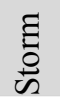 & - & 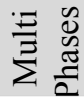 \\
\hline
\end{tabular}

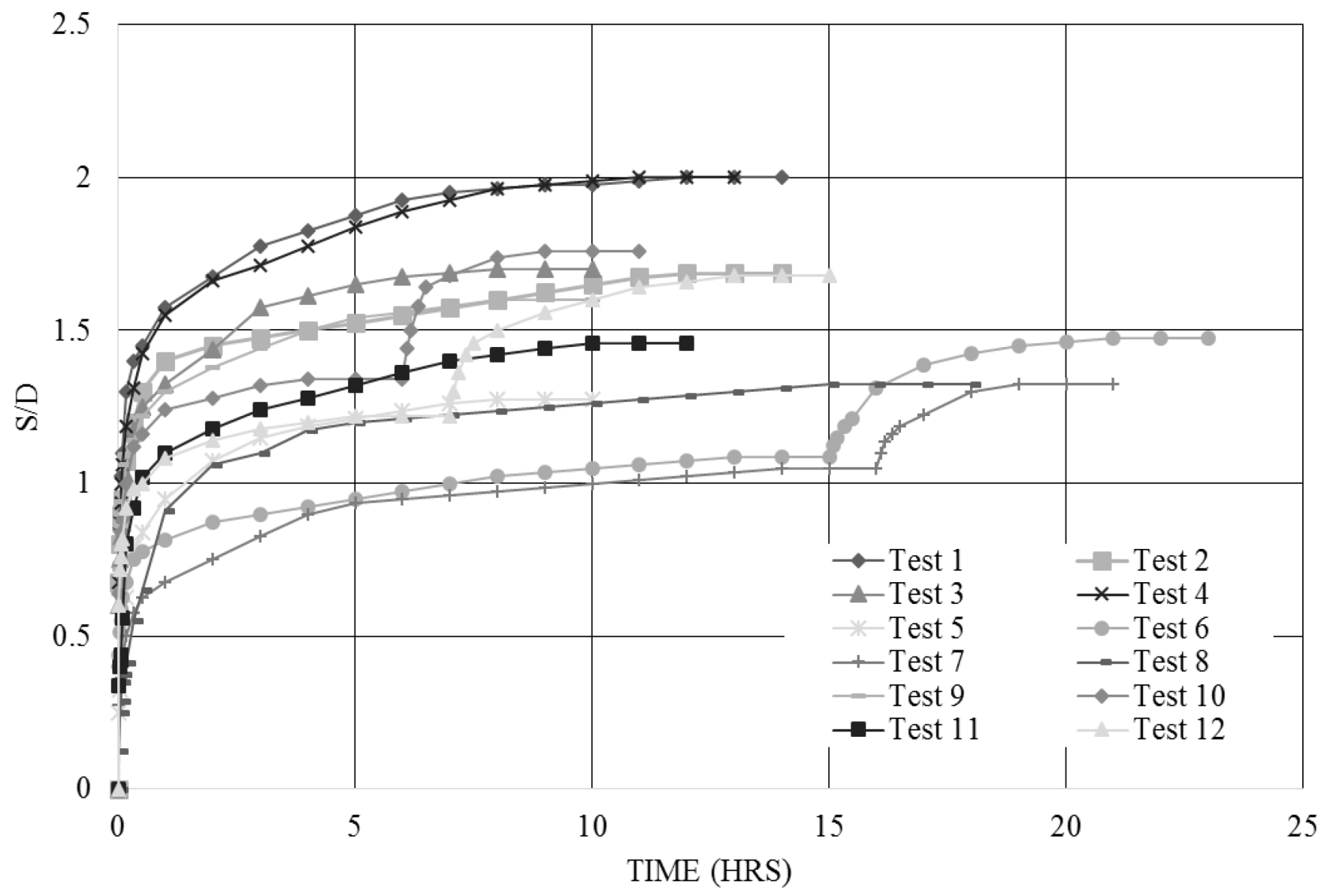

Figure 3: Summary of scour development for the different tests. 


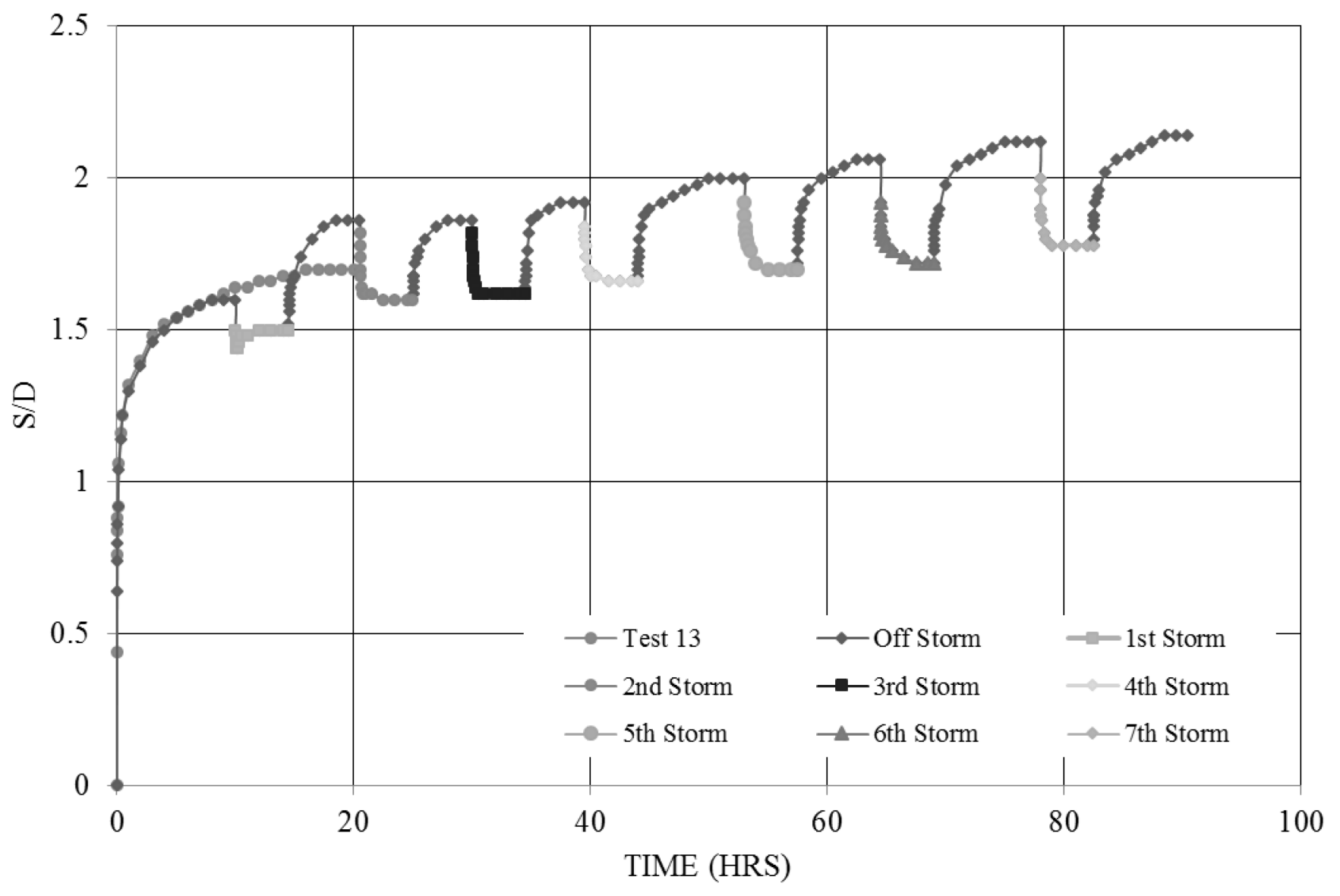

Figure 4: Multi phases scour development test.

\section{DISCUSSION}

\subsection{Effect of compaction on scour process:}

Increasing the density of soil around a pile has an effect on the rate of scour development but not on equilibrium scour depth. This is clear from the final scour depths in the two tests with equivalent conditions. Figure 3 (test 1 vs. test 4 and test 2 vs. test 3 ) and (test 5 vs. test 8 ) provide a comparison between compacted and un-compacted cases for two flow velocities. It is clear that the compacted sand, both for vibrated and un-vibrated tests, inhibits the scour process but has no effect on equilibrium scour depth.

It is generally accepted that scour depth scales with pile diameter. However, this does depend on parameters such as the grain size to pile diameter ratio as discussed by Lee and Sturm (2009). The nondimensional scour depth for the $25 \mathrm{~mm}$ pile is significantly larger than for the $40 \mathrm{~mm}$ pile. This is in agreement with the literature, and is due to the higher ratio of grain size to pile diameter in this case.

\subsection{Effect of vibration on scour process:}

The results show that vibration produces a reduction of local scour depth by causing sand particles to cascade down into the scour hole, see figure 3 (compare test 1 with test 2). Comparing these two cases, the scour depth in the first half hour of tests developed more rapidly for the vibrated case than for the case without vibration. However, at equilibrium this was not the case: final depth of the scour hole for the vibrated test was about $15 \%$ less than for the test without vibration, but with greater lateral extent.

Combinations of vibrated and un-vibrated conditions were investigated to represent real situations when a structure in the offshore environment faces a storm and then a rest period during which a normal scour hole will develop. Figure 3 (test 6, 7, 10 and 12) represent tests starting with the pile being vibrated until it reaches equilibrium, followed by a period with no vibration during which a normal scour hole is formed. The results show that the presence of vibration at the start of the scour process has the potential to increase the depth of scour significantly.

Figure 4 shows the time evolution of scour for a test with a continuous sequence of periods with and without vibration (test 14). This test started with normal scour without vibration until equilibrium scour depth was reached. There was then a period of 4.5 hours during which vibration was applied. This was followed by another period without vibration, and so on. It is clear from this test that the sequence of simulated storms leads to a scour hole more than $20 \%$ deeper and wider than the scour without vibration (test13). 


\section{CONCLUSIONS}

a) Sediment compaction can cause a slight change in the rate of development of scour but it has no effect on the equilibrium scour depth compared to un-compacted sand.

b) Scour depth is reduced by the effects of structural vibration due to the re-profiling process which produces a wider and shallower hole.

c) Scour depth is increased significantly by a sequence of alternating periods with and without structural vibration. This is caused by sediment backfilling during a vibration periods and being scoured during periods of no vibration. This situation might be experienced during a series of severe storms.

d) These results occur over a range of velocities in the clear water regime.

\section{REFERENCES}

Adhikari, S., and Bhattacharya, S., 2010. Vibrations of windturbines considering soil-structure interaction. J. Wind and Structures, 14 (2), 85-112.

Bhattacharya, S., Nikitas, N., Garnsey, J., Alexander, N.A., Cox, J., Lombardi, D., MuirWood, D., and Nash, D.F.T., 2013. Observed dynamic soil-structure interaction in scale testing of offshore wind turbine foundations. J. Soil Dynamics and Earthquake Engineering, 54, 47-60.

Damgaard, M., Ibsen, L.B., Andersen, L.V., and Andersen, J.K.F., 2013. Cross-wind modal properties of offshore wind turbines identified by full scale testing. Journal of Wind Engineering and Industrial Aerodynamics, 116, 94-108.

Damgaard, M., Bayat, M., Andersen, L.V., and Ibsen, L.B., 2014. Assessment of the dynamic behaviour of saturated soil subjected to cyclic loading from offshore monopile wind turbine foundations. J. Computers and Geotechnics, 61, 116-126.

Foglia, A., Gottardib, G., Govonib, L., and Ibsen, L.B., 2015. Modelling the drained response of bucket foundations for offshore wind turbines under general monotonic and cyclic loading. J. Applied Ocean Research, 52, 80-91.

Harrick, J.E. and Jones, T.L., 2002. A Dynamic Cone Penetrometer for Measuring Soil Penetration Resistance. Soil Sci. Soc. Am. J., 66, 1320-1324.

Harte, M., Basu, B., and Nielsen, S.R.K., 2012. Dynamic analysis of wind turbines including soil-structure interaction. J. Engineering Structures, 45, 509-518.

Hoffmans, G.J.C.M., and Verheij, H.J., 1997. Scour Manual. Balkema.

Lee, S.O., and Sturm, T.W., 2009. Effect of Sediment Size Scaling on Physical Modelling of Bridge Pier Scour. Journal of Hydraulic Engineering, 135(10), 793-802 pp.

Melville, B.W., and Coleman, S.E., 2000. Bridge Scour. Water Resources Publications, LLC, Colorado, USA, 550 pp.

Phan, T.L., McInerney, M.A., and Powell, M.D., 2007. Methodology for Development of Design Criteria for Joint Hurricane Wind Speed and Storm Surge Event: Proof of Concept. NIST Technical Note 1482.
Sumer, B.M., and Fredsoe, J., 2002. The mechanics of scour in the marine environment, World Scientific, Singapore, 539 pp.

Sumer, B.M., Whitehouse, R.J.S., and Torum, A., 2001. Scour around coastal structures: summery of recent research.

Tempel, J.V.D. and Molenaar, D.P., 2002. Wind Turbine Structural Dynamics - A Review of the Principles for Modern Power Generation, Onshore and Offshore. J. Wind Engineering, 24 (4), 211-220.

Whitehouse, R.J.S., 1998. Scour at marine structures: a manual for practical applications, Thomas Telford, London, $207 \mathrm{pp}$.

Yu, L., Zhou, Q., and Liu, J., 2015. Experimental study on the stability of plate anchors in clay under cyclic loading. Theoretical and Applied Mechanics Letters 5, 93-96. 